\title{
Season, Age and Sex-Related Differences in Incidental Magnetic Resonance Imaging Findings of Paranasal Sinuses in Adults
}

\author{
Original Investigation \\ Meltem Özdemir (1), Rasime Pelin Kavak (1) \\ Department of Radiology, University of Health Sciences, Dışkapı Yıldırım Beyazıt Training and Research Hospital, Ankara, Turkey
}

Abstract

ORCID IDs of the authors: M.0̈. 0000-0002-7388-2871; R.P.K. 0000-0001-9782-0029.

Cite this article as: Özdemir M, Kavak RP. Season, Age and Sex-Related Differences in Incidental Magnetic Resonance Imaging Findings of Paranasal Sinuses in Adults. Turk Arch Otorhinolaryngol 2019; 57(2): 61-7.

\section{Corresponding Author:} Meltem Özdemir; meltemkaan99@gmail.com

Received Date: 30.01.2019

Accepted Date: 03.05.2019

DOl: 10.5152/ta0.2019.4142

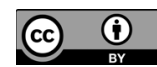

Content of this journal is licensed under a Creative Commons Attribution 4.0 International License.

Available online at www.turkarchotolaryngol.net
Objective: The purpose of the current study was to investigate the prevalence of incidental paranasal sinus abnormalities on brain magnetic resonance imaging (MRI). We also aimed to assess the season, the age and sex-related differences in the frequencies of these abnormalities.

Methods: Paranasal sinus cavities of 839 patients who underwent brain MRI for suspected intracranial pathology were retrospectively evaluated for the presence of incidental abnormalities. Two study groups were established according to the season in which the MRI examinations were performed, and the prevalences of the incidental sinusal abnormalities in both winter and summer were calculated. The relation of the incidental sinusal abnormalities to age and sex were also analyzed.

Results: Of the 839 patients, $45.5 \%$ showed one or more sinusal abnormalities. The prevalence of the sinusal abnormalities was significantly higher in winter
$(50.6 \%)$ than in summer $(40.3 \%)(\mathrm{p}=0.003)$. While sphenoidal sinus lesions did not show significant seasonality ( $p>0.05)$, frontal, maxillary and ethmoidal sinus lesions were significantly more common in winter than in summer $(\mathrm{p}<0.05)$. In both summer and winter, incidental sinusal abnormalities among men were significantly higher than among women ( $p$ values of 0.013 and 0.033 , respectively). There was no significant relationship between incidental sinus abnormalities and age in either season ( $p>0.05)$.

Conclusion: Paranasal sinus abnormality is a frequent incidental brain MRI finding which is more commonly detected in winter. Awareness of incidental paranasal sinus abnormalities and knowledge of its frequency contribute positively to clinical applications.

Keywords: Magnetic resonance imaging, incidental findings, paranasal sinuses, sinusitis

\section{Introduction}

The rapid developments in imaging technologies and the increase in the use of these methods significantly increased the detection frequency of incidentally discovered pathologies. Magnetic resonance imaging (MRI) is an extensively used imaging method for suspected intracranial pathology and may depict incidental abnormalities unrelated to the brain $(1,2)$. A wide range of sinus abnormalities, including inflammatory findings, can be visualized on MRI performed for the purpose of brain scanning $(2,3)$. It is shown that there is a significant correlation between the prevalence of incidental paranasal sinus abnormalities (IPSA) detected in MRI and the presence of clinical symptoms associated with paranasal sinus diseases. And it is recommended that this should be taken into consideration in the clinical management of the patients with IPSA (4-7). On the other hand, there are also publications reporting no significant relationship between the clinical symptoms and IPSA and advocating that medical treatment should be administered only to symptomatic patients (8-10). Since currently a standardized clinical approach to these lesions has not been established, the management of IPSA constitutes a growing concern in clinical practice (11).

According to the previous studies, the prevalence of IPSA on brain MRI shows variations within a wide range (29.5-66\%), probably depending on the climatic characteristics of the geographic region where the studies were carried out. In addition to the variations in the prevalence, the relation of these findings to the season as well as to age and sex show inconsistency among previously reported studies (4-14). The 
purpose of the current study was to investigate the prevalence of IPSA identified on brain MRI. We also aimed to assess the season, age and sex-related differences in these abnormalities.

\section{Methods}

\section{Patient population and study design}

Paranasal sinus cavities of 839 patients who underwent brain MRI between Jan 1, 2017 and Jan 1, 2018 in our institution for suspected intracranial pathology were retrospectively evaluated for the presence of paranasal sinus abnormalities. There were 322 men and 517 women with a mean age of 41.19 years (range: 20 to 72). As the study was conducted by the review of the images recorded in the Picture Archiving and Communication System (PACS) of our institution, patient consent forms could not be obtained. However, institutional review board approval was obtained before the study was initiated. Approval was obtained from the Ethics Committee of the University of Health Sciences, Dışkapı Yıldırım Beyazıt Training and Research Hospital (Approval Date: 17 Jan 2019; No: 58/04).

Two study groups were established according to the season in which the MRI examinations were performed. The winter season was defined as November through March, and the summer season was defined as April through October. The winter group included $427 \mathrm{pa}-$ tients, and the remaining 412 patients constituted the summer group.

\section{MRI protocol and image analysis}

Magnetic resonance imaging of the head was performed on a $1.5 \mathrm{~T}$ unit (Magnetom Aera; Siemens, Erlangen, Germany)
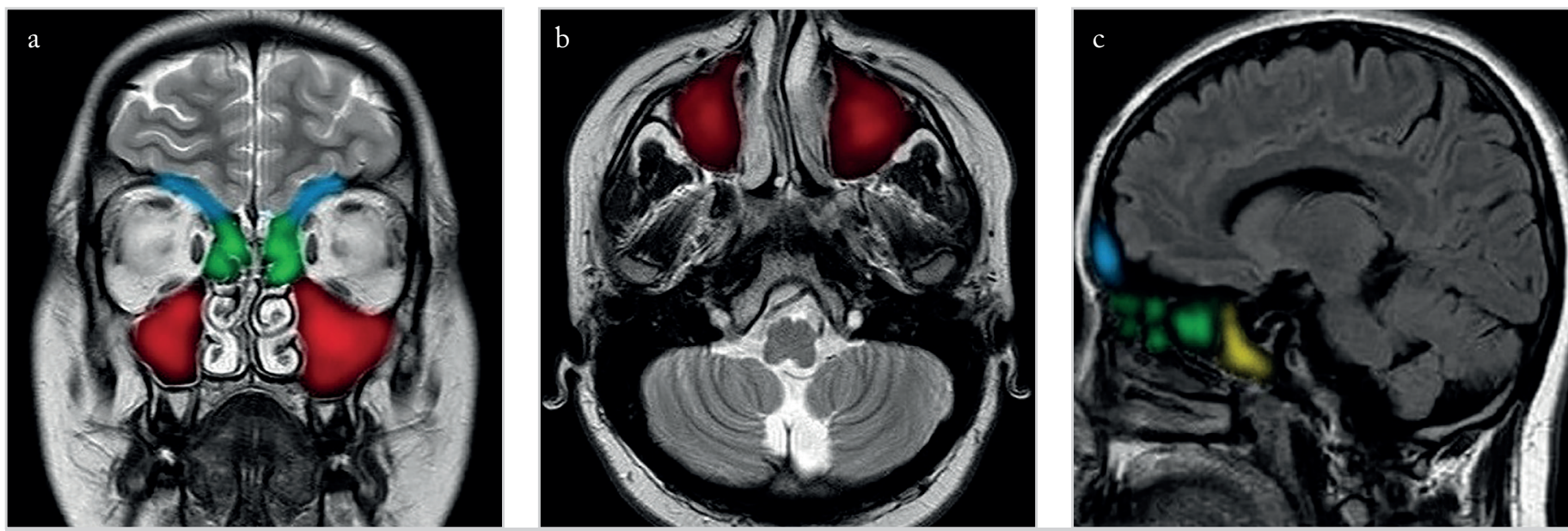

Figure 1. a-c. Coronal T2-weighted (a), axial T2-weighted (b), and sagittal FLAIR (c) images showing the frontal (blue), ethmoid (green), maxillary (red) and sphenoid (yellow) sinuses
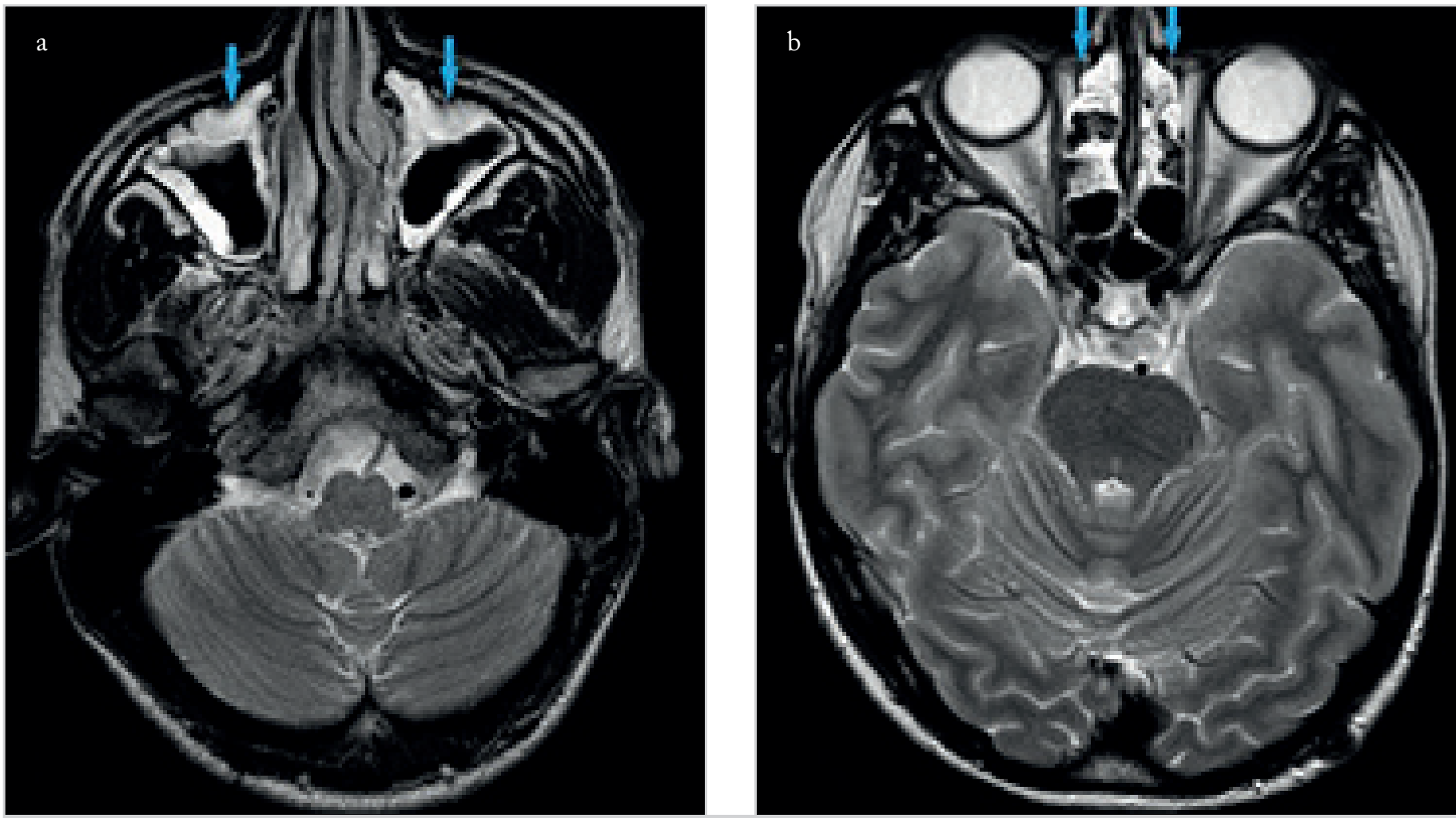

Figure 2. a, b. Mucosal thickening as seen in the maxillary (a) and ethmoid (b) sinuses (blue arrows) 

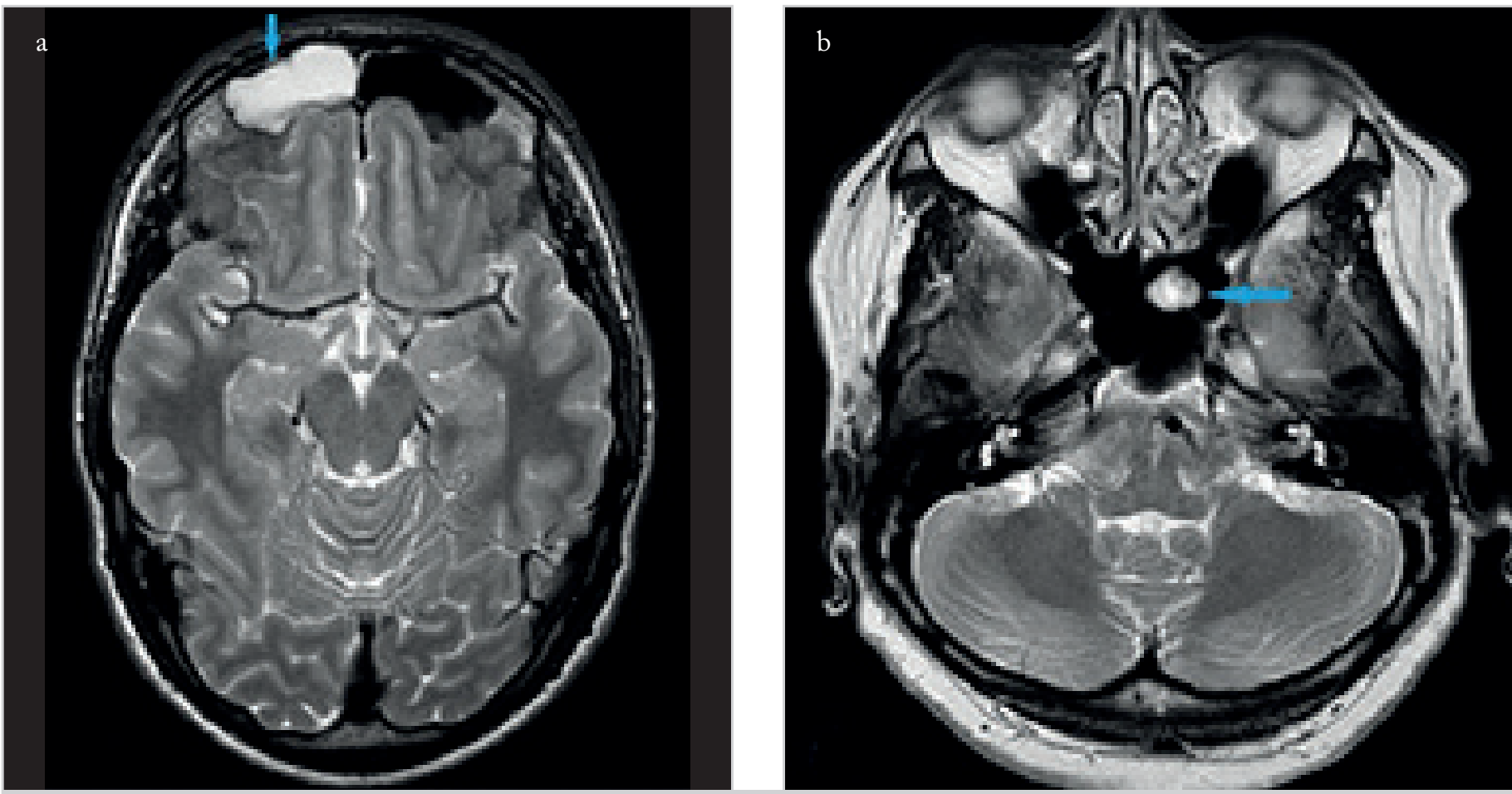

Figure 3. a, b. Retention cysts as seen in the frontal (a) and sphenoid (b) sinuses (blue arrows)
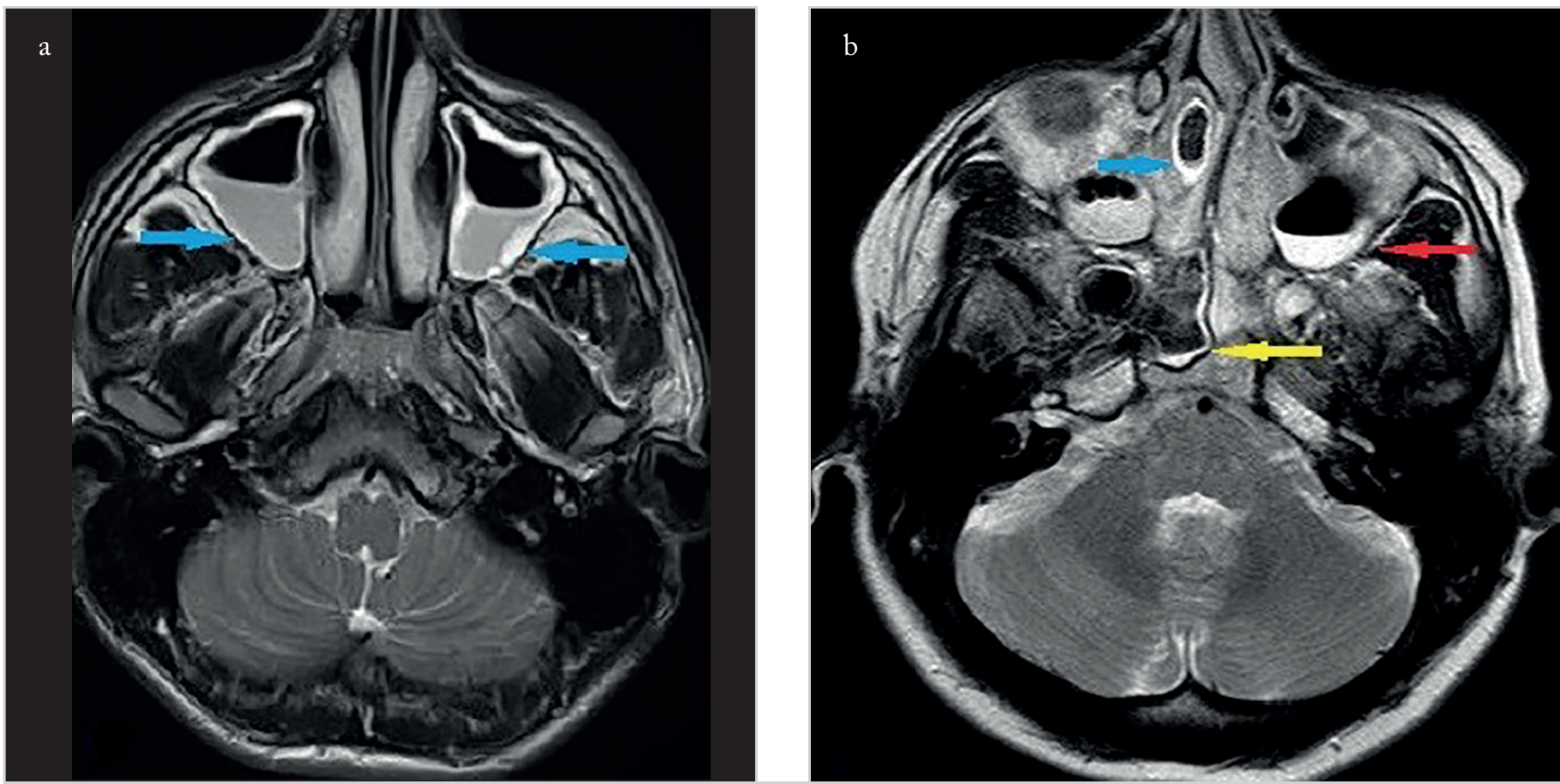

Figure 4. a, b. Fluid collection as seen in the maxillary (a) and ethmoid (b) sinuses (blue arrows). In figure b, there is a fluid collection in also the maxillary (red arrow) and the sphenoid (yellow arrow) sinuses

with a 20-channel head-neck coil. The imaging protocol constituted the following five routine sequences: axial T1-weighted (repetition time [TR]/echo time [TE]: 348/8.9 ms, voxel size: $0.7 \times 0.7 \times 0.5 \mathrm{~mm}$, field of view [FOV]: $23 \times 23 \mathrm{~cm}$, slice thickness: $5 \mathrm{~mm}$ ); axial T2-weighted (TR/TE: 4160/102 ms, voxel size: $0.6 \times 0.6 \times 5.0 \mathrm{~mm}$, FOV: $23 \times 23 \mathrm{~cm}$, slice thickness: $5 \mathrm{~mm}$ ); axial FLAIR (TR/TE: 8000/86 ms, voxel size: $0.7 \times 0.7 \times 5.0 \mathrm{~mm}$, FOV: $23 \times 23 \mathrm{~cm}$, slice thickness: $5 \mathrm{~mm}$ ); coronal T2-weighted (TR/TE: $4730 / 94 \mathrm{~ms}$, voxel size: $0.6 \times 0.6 \times 5.0 \mathrm{~mm}, \mathrm{FOV}$ :
$22 \times 22 \mathrm{~cm}$, slice thickness: $5 \mathrm{~mm}$ ), and sagittal FLAIR (TR/TE: 9000/87 ms, voxel size: $0.4 \times 0.4 \times 5.0 \mathrm{~mm}$, FOV: $23 \times 23 \mathrm{~cm}$, slice thickness: $5 \mathrm{~mm}$ ).

Each paranasal sinus was examined separately (the left and the right frontal, anterior ethmoidal, maxillary, posterior ethmoidal, and sphenoid sinuses) on the sections obtained in all three orthogonal planes (Figure 1). The sinusal lesions were classified as follows: 
1. Mucosal thickening: Mucosal thickening of $>3 \mathrm{~mm}$ was accepted as a positive finding (Figure 2).

2. Retention cyst and polyp: As retention cysts and polyps cannot be exactly differentiated on MRI, they were joined in the same group. A hemispherical or dome-shaped, well-circumscribed, homogeneous area with a smooth outline within the sinus was accepted as a positive finding (Figure 3).

3. Fluid collection: An air-fluid level within the sinus was accepted as a positive finding (Figure 4).

Two experienced radiologists reviewed the paranasal sinuses independently and in a blinded manner for the clinical data of the patients. In the cases where there was discrepancy in the two interpretations of the images, a common re-examination was performed, and the final decision was made by consensus.

\section{Statistical Analysis}

Statistical analyses of the current study were performed using Statistical Package for the Social Sciences for Windows version 24.0 (IBM Corp.; Armonk, NY, USA), and a p value $<0.05$ was accepted as statistically significant. The Chi-square test was applied to investigate the relationship between two categorical variables. Multivariate Binary logistic regression analysis was performed to adjust gender effect on comparison of findings and locations between seasons.

Table 1. Baseline characteristics of the study population

\begin{tabular}{l|c|c|c|c}
\hline \multicolumn{2}{|c|}{} & Summer $(\mathbf{n}=412)$ & Winter $(\mathbf{n}=427)$ & $p$ \\
\hline $\begin{array}{l}\text { Age } \\
\text { (years) }\end{array}$ & $20-29$ & $128(31.1)$ & $137(32.1)$ & 0.881 \\
\cline { 2 - 4 } & $30-39$ & $90(21.8)$ & $102(23.9)$ & \\
\cline { 2 - 4 } & $40-49$ & $66(16)$ & $61(14.3)$ & \\
\cline { 2 - 4 } & $50-59$ & $63(15.3)$ & $59(13.8)$ & \\
\cline { 2 - 4 } & $>60$ & $65(15.8)$ & $68(15.9)$ & \\
\hline \multirow{2}{*}{ Gender } & Female & $224(54.4)$ & $293(68.6)$ & \multirow{2}{*}{$0.001^{*}$} \\
\cline { 2 - 4 } & Male & $188(45.6)$ & $134(31.4)$ & \\
\hline
\end{tabular}

*statistical significance

Table 2. The prevalence of incidental paranasal sinus abnormalities in the summer and winter groups

\begin{tabular}{|c|c|c|c|c|}
\hline & Summer $(n=412)$ & Winter $(n=427)$ & $\mathrm{p}$ & $\mathrm{p}_{\text {adjusted }}$ \\
\hline \multicolumn{5}{|l|}{ Finding } \\
\hline At least one finding & $166(40.3)$ & $216(50.6)$ & $0.003^{*}$ & $0.001^{*}$ \\
\hline $\mathrm{MT}$ & $128(31.1)$ & $183(42.9)$ & $0.001^{*}$ & $0.001^{*}$ \\
\hline $\mathrm{RC}-\mathrm{P}$ & 79 (19.2) & $83(19.4)$ & 0.923 & 0.739 \\
\hline $\mathrm{FC}$ & $16(3.9)$ & $10(2.3)$ & 0.198 & 0.376 \\
\hline \multicolumn{5}{|l|}{ Location } \\
\hline $\mathrm{F}$ & $39(9.5)$ & $58(13.6)$ & 0.062 & $0.021^{*}$ \\
\hline $\mathrm{AE}$ & $61(14.8)$ & $94(22)$ & $0.007^{*}$ & $0.002^{*}$ \\
\hline $\mathrm{M}$ & $137(33.3)$ & $179(41.9)$ & $0.010^{*}$ & $0.003^{*}$ \\
\hline $\mathrm{PE}$ & $58(14.1)$ & $87(20.4)$ & $0.016^{*}$ & 0.004 \\
\hline S & $46(11.2)$ & $57(13.3)$ & 0.335 & 0.179 \\
\hline
\end{tabular}

MT: mucosal thickening; RC-P: retention cyst and polyp; FC: fluid collection; F: frontal sinus; AE: anterior ethmoid sinus; M: maxillary sinus; PE: posterior ethmoid sinus; S: sphenoid sinus; $\mathrm{P}_{\text {adjusted }}: \mathrm{p}$ adjusted by gender

*statistical significance

\section{Results}

Baseline characteristics of the study population are given in $\mathrm{Ta}^{-}$ ble 1 . There was no significant difference between the summer and the winter groups in terms of age distribution $(\mathrm{p}=0.881)$. The difference between the number of men and women in the summer group was not significant $(\mathrm{p}=0.228)$, but there were significantly more women than men in the winter group $(p=0.001)$.

Of the current sample of 839 patients, 382 (45.5\%) showed one or more sinusal abnormalities. Mucosal thickening was the most common abnormality (37.1\%), and the maxillary sinus was the most commonly

The prevalence of IPSA in the summer and winter groups are shown in Table 2. In both groups, mucosal thickening and the maxillary sinus were the most common finding and location, respective1y. The prevalence of at least one IPSA in the winter group (50.6\%) was significantly higher than that in the summer group (40.3\%) $(\mathrm{p}=0.003)$. While the frequencies of frontal and sphenoid sinus lesions did not show significant differences between the two groups ( $p>0.05)$, the frequencies of lesions of maxillary and ethmoid sinuses were significantly higher in the winter group compared to the summer group $(\mathrm{p}<0.05)$. Using multivariate logistic regression analysis, the difference between the winter and summer prevalences of frontal sinus lesions reached a significant value. However, gender adjustment did not change the comparison data of frequencies for the other locations and the findings between seasons.

The prevalence of IPSA according to sex in the summer and winter groups are shown in Table 3. In both groups, the prevalence of at least one IPSA among men was significantly higher than that among women $(\mathrm{p}<0.05)$. In both summer and winter groups, the frequencies of maxillary sinus lesions did not show significant differences between the two genders ( $p>0.05)$, while the frequencies of frontal and ethmoid sinus lesions were significantly higher in men than in women $(\mathrm{p}<0.05)$.

The prevalence of IPSA according to age in the summer and the winter groups are shown in Table 4 and 5, respectively. There was no significant relationship between IPSA and age in either group $(p>0.05)$. affected sinus (37.7\%), followed by the anterior ethmoid sinus (18.5\%). 


\section{Discussion}

We retrospectively evaluated the paranasal sinus cavities of 839 patients who underwent brain MRI. We recorded at least one
IPSA in $45.5 \%$ of the study population with mucosal thickening being the most common abnormality (37.1\%), and the maxillary sinus being the most commonly affected sinus (37.7\%). The fre-

Table 3. The prevalence of incidental paranasal sinus abnormalities according to sex in the summer and winter groups

\begin{tabular}{|c|c|c|c|c|c|c|}
\hline $\begin{array}{c}\text { Female } \\
(\mathbf{n}=224)\end{array}$ & $\begin{array}{c}\text { Summer } \\
\text { Male } \\
(\mathbf{n}=188)\end{array}$ & $\mathbf{p}$ & $\begin{array}{c}\text { Female } \\
(\mathbf{n}=293)\end{array}$ & $\begin{array}{c}\text { Male } \\
(\mathbf{n}=134)\end{array}$ & $\mathbf{p}$ \\
\hline $78(34.8)$ & $88(46.8)$ & $0.013^{*}$ & $138(47.1)$ & $78(58.2)$ & $0.033^{*}$ \\
\hline $58(25.9)$ & $70(37.2)$ & $0.013^{*}$ & $112(38.2)$ & $71(53)$ & $0.004^{*}$ \\
\hline $38(17)$ & $41(21.8)$ & 0.213 & $53(18.1)$ & $30(22.4)$ & 0.298 \\
\hline $7(3.1)$ & $9(4.8)$ & 0.384 & $8(2.7)$ & $2(1.5)$ & 0.433 \\
\hline
\end{tabular}

Finding

At least one finding

MT

$\mathrm{RC}-\mathrm{P}$

$\mathrm{FC}$

Location

F

$\mathrm{AE}$

$\mathrm{M}$

$\mathrm{PE}$

$\mathrm{S}$

\begin{tabular}{|c|c|c|c|}
\hline $15(6.7)$ & $24(12.8)$ & $0.036^{*}$ & $32(10.9)$ \\
\hline $26(11.6)$ & $35(18.6)$ & $0.046^{*}$ & $54(18.4)$ \\
\hline $67(29.9)$ & $70(37.2)$ & 0.116 & $113(38.6)$ \\
\hline $23(10.3)$ & $35(18.6)$ & $0.015^{*}$ & $50(17.1)$ \\
\hline $17(7.6)$ & $29(15.4)$ & $0.012^{*}$ & $35(11.9)$ \\
\hline
\end{tabular}

\begin{tabular}{|c|c|c|c|}
\hline $15(6.7)$ & $24(12.8)$ & $0.036^{*}$ & $32(10.9)$ \\
\hline $26(11.6)$ & $35(18.6)$ & $0.046^{*}$ & $54(18.4)$ \\
\hline $67(29.9)$ & $70(37.2)$ & 0.116 & $113(38.6)$ \\
\hline $23(10.3)$ & $35(18.6)$ & $0.015^{*}$ & $50(17.1)$ \\
\hline $17(7.6)$ & $29(15.4)$ & $0.012^{*}$ & $35(11.9)$ \\
\hline
\end{tabular}

\begin{tabular}{|c|c|c|c|}
\hline $15(6.7)$ & $24(12.8)$ & $0.036^{*}$ & $32(10.9)$ \\
\hline $26(11.6)$ & $35(18.6)$ & $0.046^{*}$ & $54(18.4)$ \\
\hline $67(29.9)$ & $70(37.2)$ & 0.116 & $113(38.6)$ \\
\hline $23(10.3)$ & $35(18.6)$ & $0.015^{*}$ & $50(17.1)$ \\
\hline $17(7.6)$ & $29(15.4)$ & $0.012^{*}$ & $35(11.9)$ \\
\hline
\end{tabular}

$\mid$

\begin{tabular}{|l|l|}
\hline $26(19.4)$ & $0.018^{*}$ \\
\hline $40(29.9)$ & $0.008^{*}$ \\
\hline $66(49.3)$ & 0.058 \\
\hline $37(27.6)$ & $0.012^{*}$ \\
\hline $22(16.4)$ & 0.207 \\
\hline
\end{tabular}

sinus

*statistical significance

Table 4. The prevalence of incidental paranasal sinus abnormalities according to age in the summer group

Age (yrs)

Mucosal thickening

20-29

30-39

40-49

50-59

$>60$

Total

$\mathrm{p}$

Retention cyst and polyp

\begin{tabular}{|c|c|c|c|c|c|c|}
\hline $20-29$ & 128 & $2(1.5)$ & $3(2.2)$ & $29(21.2)$ & $2(1.5)$ & $4(2.9)$ \\
\hline $30-39$ & 90 & $2(2)$ & $2(2)$ & $15(14.7)$ & $2(2)$ & $0(0)$ \\
\hline $40-49$ & 66 & $0(0)$ & $0(0)$ & $8(13,1)$ & $0(0)$ & $1(1.6)$ \\
\hline $50-59$ & 63 & $0(0)$ & $0(0)$ & $12(20.3)$ & $2(3.4)$ & $1(1.7)$ \\
\hline$>60$ & 65 & $2(2.9)$ & $1(1.5)$ & $11(16.2)$ & $2(2.9)$ & $0(0)$ \\
\hline Total & 412 & $6(1.4)$ & $6(1.4)$ & 75 (17.6) & $8(1.9)$ & $6(1.4)$ \\
\hline $\mathrm{p}$ & & 0.541 & 0.636 & 0.551 & 0.492 & 0.159 \\
\hline \multicolumn{7}{|c|}{ Fluid collection } \\
\hline $20-29$ & 128 & $1(0.8)$ & $2(1.6)$ & $3(2.3)$ & $1(0.8)$ & $1(0.8)$ \\
\hline $30-39$ & 90 & $2(2.2)$ & $3(3.3)$ & $2(2.2)$ & $1(1.1)$ & $2(2.2)$ \\
\hline $40-49$ & 66 & $0(0)$ & $0(0)$ & $1(1.5)$ & $0(0)$ & $2(3)$ \\
\hline $50-59$ & 63 & $0(0)$ & $0(0)$ & $1(1.6)$ & $0(0)$ & $0(0)$ \\
\hline$>60$ & 65 & $1(1.5)$ & $0(0)$ & $1(1.5)$ & $0(0)$ & $1(1.5)$ \\
\hline Total & 412 & $4(1.0)$ & $5(1.2)$ & $8(1.9)$ & $2(0.5)$ & $6(1.5)$ \\
\hline $\mathrm{p}$ & & 0.558 & 0.208 & 0.989 & 0.753 & 0.584 \\
\hline
\end{tabular}

yrs: years N: number; F: frontal sinus; AE: anterior ethmoid sinus; M: maxillary sinus; PE: posterior ethmoid sinus; S: sphenoid sinus *statistical significance 
Table 5. The prevalence of incidental paranasal sinus abnormalities according to age in the winter group.

\begin{tabular}{|c|c|c|c|c|c|c|}
\hline Age (yrs) & $\mathrm{N}$ & $\mathbf{F}$ & $\mathrm{AE}$ & M & $\mathrm{PE}$ & $\mathrm{S}$ \\
\hline \multicolumn{7}{|c|}{ Mucosal thickening } \\
\hline $20-29$ & 137 & $15(10.9)$ & $29(21.2)$ & $46(33.6)$ & $27(19.7)$ & $16(11.7)$ \\
\hline $30-39$ & 102 & 19 (18.6) & $27(26.5)$ & $35(34.3)$ & $22(21.6)$ & $18(17.6)$ \\
\hline $40-49$ & 61 & $11(18)$ & $14(23)$ & $20(32.8)$ & $11(18)$ & $11(18)$ \\
\hline $50-59$ & 59 & $5(8.5)$ & $9(15.3)$ & $17(28.8)$ & $10(16.9)$ & $6(10.2)$ \\
\hline$>60$ & 68 & $5(7.4)$ & $13(19.1)$ & $24(35.3)$ & $13(19.1)$ & $5(7.4)$ \\
\hline Total & 427 & $55(12.9)$ & $92(21.5)$ & $142(33.3)$ & $83(19.4)$ & $56(13.1)$ \\
\hline $\mathrm{p}$ & & 0.137 & 0.178 & 0.227 & 0.292 & 0.669 \\
\hline \multicolumn{7}{|c|}{ Retention cyst and polyp } \\
\hline $20-29$ & 137 & $3(2.3)$ & $3(2.3)$ & $24(18.8)$ & $3(2.3)$ & $5(3.9)$ \\
\hline $30-39$ & 102 & $1(1.1)$ & $1(1.1)$ & $19(21.1)$ & $1(1.1)$ & $0(0)$ \\
\hline $40-49$ & 61 & $0(0)$ & $1(1.5)$ & $8(12.1)$ & $1(1.5)$ & $2(3)$ \\
\hline $50-59$ & 59 & $0(0)$ & $0(0)$ & $10(15.9)$ & $0(0)$ & $0(0)$ \\
\hline$>60$ & 68 & $0(0)$ & $0(0)$ & $9(13.8)$ & $0(0)$ & $0(0)$ \\
\hline Total & 427 & $4(1)$ & $5(1.2)$ & $70(17)$ & $5(1.2)$ & $7(1.7)$ \\
\hline $\mathrm{p}$ & & 0.351 & 0.559 & 0.560 & 0.373 & $0.029^{*}$ \\
\hline \multicolumn{7}{|c|}{ Fluid collection } \\
\hline $20-29$ & 137 & $1(0.7)$ & $0(0)$ & $2(1.5)$ & $1(0.7)$ & $0(0)$ \\
\hline $30-39$ & 102 & $0(0)$ & $0(0)$ & $2(2)$ & $1(1)$ & $2(2)$ \\
\hline $40-49$ & 61 & $1(1.6)$ & $0(0)$ & $0(0)$ & $0(0)$ & $1(1.6)$ \\
\hline $50-59$ & 59 & $0(0)$ & $1(1.7)$ & $0(0)$ & $0(0)$ & $1(1.7)$ \\
\hline$>60$ & 68 & $0(0)$ & $0(0)$ & $0(0)$ & $0(0)$ & $0(0)$ \\
\hline Total & 427 & $2(0.5)$ & $1(0.2)$ & $4(0.9)$ & $2(0.5)$ & $4(0.9)$ \\
\hline $\mathrm{p}$ & & 0.546 & 0.181 & 0.504 & 0.798 & 0.436 \\
\hline
\end{tabular}

yrs: years; N: number; F: frontal sinus; AE: anterior ethmoid sinus; M: maxillary sinus; PE: posterior ethmoid sinus; S: sphenoid sinus

*statistical significance

quency of sphenoid sinus lesions did not show significant differences between summer and winter. However, the frequencies of frontal, maxillary and ethmoid sinus lesions were significantly higher in winter than in summer. While the prevalence of at least one IPSA among men was significantly higher than that among women in both seasons, there was no significant relationship between IPSA and age in either season.

Owing to its excellent soft tissue resolution, MRI can characterize sinusal inflammation by differentially depicting mucosal inflammations, fluid collections, cysts and polyps (3). Although the indication of MRI is limited in the evaluation of sinonasal disease, radiologists assessing brain MRIs are quite familiar with the MRI appearances of sinusal inflammatory changes. The previously reported prevalences of IPSA on brain MRI studies show variations between $29.5 \%$ and $66 \%$ (4-14). The climatic variations among the geographic regions in which the studies were carried out might have caused the variations in the detection rates of IPSA. In their study held in a Malaysian population, Nazri et al. (7) reported the prevalence of IPSA as $29.5 \%$, whereas Hansen et al. (14) reported a prevalence of $66 \%$ for IPSA in the Norwegian climate. The current study was conducted in Ankara, Turkey, where the reported average winter and summer temperatures are $3.6^{\circ} \mathrm{C}$ and $23.4^{\circ} \mathrm{C}$, respectively (15).
We found IPSA in $45.5 \%$ of our study population and recorded a significantly higher IPSA frequency in the winter (50.6\%) than in the summer (40.3\%).

There are varying data reported for the seasonality of the prevalence of IPSA. While some authors reported no difference between the summer and the winter frequencies of IPSA $(14,16)$, others noted significantly higher frequencies in winter $(5,6)$. According to our results, the frequencies of frontal, maxillary and ethmoid sinus lesions were significantly higher in winter than in summer, while the frequency of sphenoid sinus lesions did not show significant seasonal differences. A recent study showed that mucosa of the maxillary and ethmoid sinuses have higher proliferation ability and superior $\mathrm{ca}^{-}$ pacity to secrete immunomodulatory cytokines compared to that of the other regions in the sinonasal tract (17). Different regional tissue characteristics of maxillary and ethmoid sinuses may have an impact on their mucosal responses to seasonal temperature changes. And this may be the cause of the difference between paranasal sinuses in terms of the season related inflammatory manifestations.

There is inconsistency among previously reported studies concerning the relation of the frequency of IPSA to sex. In the majority of the previous studies, no significant difference was reported between men and women in terms of the frequency of IPSA 
$(5,7,16)$. However, Hansen et al. (14) noted a higher prevalence of IPSA among men than among women. Similar to the results of the study conducted by Hansen et al. (14), we recorded significantly higher prevalence of IPSA among men than among women in both the winter and the summer seasons. In a recent meta-analysis, it is reported that upper respiratory tract infections, especially sinusitis, are more common among women while men are more commonly affected by lower respiratory tract infections (18). On the other hand, there are studies reporting the male predilection of both acute and chronic sinusitis $(19,20)$. In their comprehensive review on the gender differences in the frequency, the management, and the quality of life of patients with chronic rhinosinusitis, Ference et al. (21) stated that women may be more prone to report symptoms, apply for medical support, and have a poorer self-assessment of health, which may lead to an incorrectly high prevalence of chronic rhinosinusitis among women.

In accordance with the previous data, the results of the current study showed no significant relationship between the age of the patient and the prevalence of IPSA either in summer or in winter $(5,7,16)$. Although we observed a tendency towards higher IPSA frequencies among patients in the third and fourth decades of their life compared to those in the older age groups, this did not show a statistical significance in either season.

The major limitation of our study was that we did not evaluate the relationship between the prevalence of IPSA detected by MRI and the presence of clinical symptoms of sinus pathology. Further comprehensive studies are needed for more precise and inclusive comments regarding the clinical significance of IPSA and to develop a standard clinical approach to these lesions.

\section{Conclusion}

Paranasal sinus abnormality is a frequent incidental brain MRI finding that is more commonly detected in winter. Regardless of the season, IPSA is more commonly found in men compared to women. Awareness of IPSA and knowledge of its frequency contribute positively to clinical applications.

Ethics Committee Approval: Ethics committee approval was received for this study from the Ethics Committee of University of Health Sciences, Dışkapı Y1ldırım Beyazıt Training and Research Hospital (Approval Date:17 Jan 2019; No:58/04).

Informed Consent: Informed consent was not received due to the retrospective nature of the study.

Peer-review: Externally peer-reviewed.

Author Contributions: Concept - M.Ö.; Design - M.Ö.; Supervision - M.Ö.; Resource - M.Ö., R.P.K.; Materials - M.Ö., R.P.K.; Data Collection and/or Processing - M.Ö., R.P.K.; Analysis and/or Interpretation - M.Ö., R.P.K; Literature Search - M.Ö., R.P.K; Writing - M.Ö.; Critical Reviews - M.Ö., R.P.K.

Conflict of Interest: The authors have no conflicts of interest to declare.

Financial Disclosure: The authors declared that this study has received no financial support.

\section{References}

1. Gibson LM, Paul L, Chappell FM, Macleod M, Whiteley WN, Salman RA, et al. Potentially serious incidental findings on brain and body magnetic resonance imaging of apparently asymptomatic adults: systematic review and meta-analysis. BMJ 2018; 363: k4577.

2. Kamio T,Yakushiji T,Takaki T, Shibahara T,Imoto K, Wakoh M.Incidental findings during head and neck MRI screening in 1717 patients with temporomandibular disorders. Oral Radiol 2019; 35: 135-42. [CrossRef]

3. Pulickal GG, Navaratnam AV, Nguyen T, Dragan AD, Dziedzic M, Lingam RK. Imaging sinonasal disease with MRI: Providing insight over and above CT. Eur J Radiol 2018; 102: 157-68. [CrossRef]

4. Rak KM, Newell JD 2nd, Yakes WF, Damiano MA, Luethke JM. Paranasal sinuses on MR images of the brain: significance of mucosal thickening. AJR Am J Roentgenol 1991; 156: 381-4. [CrossRef]

5. Tarp B, Fiirgaard B, Christensen T, Jensen JJ, Black FT. The prevalence and significance of incidental paranasal sinus abnormalities on MRI. Rhinology 2000; 38: 33-8.

6. del Rio A, Trost N, Tartaglia C, O'Leary SJ, Michael P. Seasonality and incidental sinus abnormality reporting on MRI in an Australian climate. Rhinology 2012; 50: 319-24. [CrossRef]

7. Nazri M, Bux SI, Tengku-Kamalden TF, Ng KW, Sun Z. Incidental detection of sinus mucosal abnormalities on CT and MRI imaging of the head. Quant Imaging Med Surg 2013; 3: 82-8.

8. Cooke LD, Hadley DM. MRI of the paranasal sinuses: incidental abnormalities and their relationship to symptoms.J Laryngol Otol 1991; 105: 278-81. [CrossRef]

9. Wani MK, Ruckenstein MJ, Parikh S. Magnetic resonance imaging of the paranasal sinuses: incidental abnormalities and their relationship to patient symptoms. J Otolaryngol 2001; 30: 257-62. [Cross Ref]

10. von Kalle T, Fabig-Moritz C, Heumann H, Winkler P. Incidental findings in paranasal sinuses and mastoid cells: a cross-sectional magnetic resonance imaging (MRI) study in a pediatric radiology department. Rofo 2012; 184: 629-34. [CrossRef]

11. Seki A, Uchiyama H, Fukushi T, Sakura O, Tatsuya K. Incidental findings of brain magnetic resonance imaging study in a pediatric cohort in Japan and recommendation for a model management protocol. J Epidemiol 2010; 20: S498-504.

12. Maly PV, Sundgren PC. Changes in paranasal sinus abnormalities found incidentally on MRI. Neuroradiology 1995; 37: 471-4. [CrossRef]

13. Patel K, Chavda SV, Violaris N, Pahor AL. Incidental paranasal sinus inflammatory changes in a British population. J Laryngol Otol 1996; 110: 649-51. [CrossRef]

14. Hansen AG, Helvik AS, Nordgård S, Bugten V, Stovner LJ, Håberg AK, et al. Incidental findings in MRI of the paranasal sinuses in adults: a population-based study (HUNT MRI). BMC Ear Nose Throat Disord 2014; 14: 13. [CrossRef]

15. Mevsimlik Sıcaklık Analizi-Meteoroloji Genel MüdürlüğüMGM. Available at: https://www.mgm.gov.tr/veridegerlendirme/ sicaklik-analizi.aspx. Date of access: Jan 212019.

16. Jafari-Pozve N, Roshanzamir N. Association between the seasonal changes and mucous retention cyst of maxillary antrum in cone beam computed tomography images in a sample population of Isfahan, Iran. Indian J Dent Res 2018; 29: 410-3. [CrossRef]

17. Cho KS, Park HY, Roh HJ, Bravo DT, Hwang PH, Nayak JV. Human ethmoid sinus mucosa: a promising novel tissue source of mesenchymal progenitor cells. Stem Cell Res Ther 2014; 5: 15. [CrossRef]

18. Falagas ME, Mourtzoukou EG, Vardakas KZ. Sex differences in the incidence and severity of respiratory tract infections. Respir Med 2007; 101: 1845-63. [CrossRef]

19. Lebovics RS, Moisa II, Ruben RJ. Sex predilection in patients with acute frontal sinusitis. Ear Nose Throat J 1989; 68: 433-4.

20. Shi JB, Fu QL, Zhang H, Cheng L, Wang YJ, Zhu DD, et al. Epidemiology of chronic rhinosinusitis: results from a cross-sectional survey in seven Chinese cities. Allergy 2015; 70: 533-9. [CrossRef]

21. Ference EH, Tan BK, Hulse KE, Chandra RK, Smith SB, Kern $\mathrm{RC}$, et al. Commentary on gender differences in prevalence, treatment, and quality of life of patients with chronic rhinosinusitis. Allergy Rhinol 2015; 6: e82-8. 